\title{
LACTOFERRIN: PROPERTIES AND APPLICATION. A REVIEW
}

\author{
Irina V. Bobreneva ${ }^{*}$, Mariya V. Rokhlova \\ Moscow State University of Food Production, Moscow, Russia
}

Keywords: antimicrobial activity, iron-binding, milk proteins, meat industry, bovine, chemical structure, food preservation, SARS-CoV

\begin{abstract}
The current state, prospects for using and priorities in studying multifunctional protein lactoferrin (LF) in the food industry are discussed. Over the last decades, the studies of iron-binding, antibacterial, antiviral and antiparasitic properties of this representative of transferrins have determined quite a wide sphere of its use. The data on the lactoferrin composition, structure and activity are presented. The authors describe the modern methods for lactoferrin extraction and production from dairy raw materials both in the domestic and foreign productions using chromatographic methods for extraction and membrane methods for production. The practical experience in its application for food production, in particular, for meat and fermented dairy products, child and sports nutrition is discussed. An effect of technological process parameters in food production on the LF activity is highlighted. The study analyses an influence of new processing technologies such as high pressure or pulsed electric field in combination with classic methods for thermal processing and drying on the structure and activity of lactoferrin in food. The reviewed studies show that the use of lactoferrin in the meat industry, especially, in finished meat products, has limitations. The data presented in the review suggest a need for searching ways of lactoferrin introduction into meat systems to obtain functional products. One of the top-priority method for LF incorporation into meat products is LF encapsulation as one of the production stages.
\end{abstract}

\section{Introduction}

Multifunctional protein lactoferrin (LF) is promising for production of different medicines, biologically active additives, cosmetic preparations, food products. It was first identified in 1939 in bovine milk. This happened due to its iron-binding capacity. Lactoferrin was classified as a member of the transferrin family along with serum transferrin and membrane ovotransferrin. Later on, it was recovered from milk of humans, guinea pigs, sheep, goats, pigs, horses, mice and dogs [1]. The primary structure of LF from human milk was discovered in 1984; then, in 1991, the structure of LF from bovine milk was determined. The amino acid sequence identity between human and bovine lactoferrin is about $70 \%$.

It is known that lactoferrin is synthesized by the epithelial cells of mammalian exocrine glands and is a constituent of different secretory liquids. It was found in saliva, lacrimal fluid, nasal discharge, digestive juice, bile, urine, seminal fluid, cervical mucus, colostrum and others [2].

The problem of studying LF properties and ways of using this component in food production has been topical over many years due to its wide functional characteristics such as the iron-binding capacity, antibacterial, antifungal, antiviral, antiparasitic activities, anti-inflammatory action, enzymatic properties [3]. Modern studies are aimed towards extending a line of LF-containing products. Attempts are made to produce not only lactoferrin-containing fermented dairy food products, but also to introduce this component into meat products. The aim of this paper is to summarize information about the recent achievements in LF production for using in food manufacture.
The main lactoferrin source is milk, which is a unique biological liquid. Its protein content varies on average from $2.9 \%$ to $3.2 \%$. Milk proteins have complex composition; they are different in terms of physico-chemical properties and functions. Milk proteins are classified into three groups. The first group includes casein and its complex of four fractions; the proportion of its fraction relative to other milk proteins is $80 \%$. The second group includes milk serum proteins accounting for $19 \%$. This group is represented by different globular proteins such as $\beta$-lactoglobulin, a-lactoglobulin, immunoglobulin and serum albumin, lactoferrin and other minor proteins. They differ from each other by structure and biological properties. The third group includes fat-globule membrane proteins accounting for only about $1 \%$ of all milk proteins.

\section{Lactoferrin}

Milk serum proteins, in particular, lactoferrin, which is the most potent antimicrobial agent in milk, have aroused considerable interest in the scientific community. This component is glycoprotein with a molecular weight of about $80 \mathrm{kDa}$. The lactoferrin composition is presented in Table 1.

The molecular structure of lactoferrin is a polypeptide chain folded into two globular homologous fragments linked with the a-helix. Each of these fragments consists of two domains, to which the iron ion is attached. The molecular structure of lactoferrin has two forms - apolactoferrin and hololactoferrin. Apolactoferrin is the iron-free lactoferrin form, which is more sensitive to the proteinase action. Hololactoferrin is the lactoferrin form containing the iron ion, which is stable and resistant to 


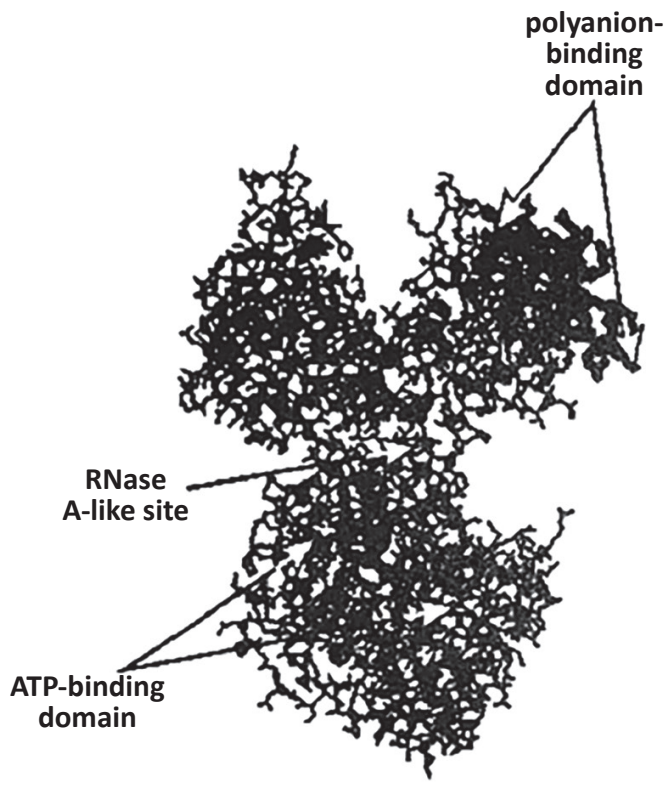

apo-LF
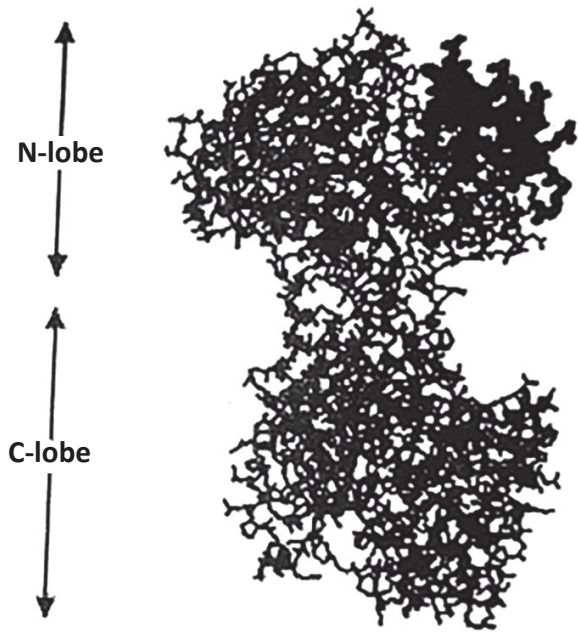

Fe-LF

Figure 1. Spatial organization of apo- and Fe- lactoferrin

the action of enzymes [4]. Figure 1 presents the apo- and Fe-lactoferrin forms.

Table 1. Lactoferrin composition

\begin{tabular}{|l|l|}
\multicolumn{1}{|c}{ Protein part } & \multicolumn{1}{|c}{ Carbohydrate part } \\
$\begin{array}{l}\text { - monomeric } \beta \text {-globulin } \\
\text { containing more than } \\
\text { 690 amino acid residues }\end{array}$ & $\begin{array}{l}\text { sialic acid residue (5-acetamido- } \\
\text { 3,5-dideoxy-D-glycero-D-galacto- } \\
\text { nonulosonic acid) }\end{array}$ \\
& - fucose (6-deoxy-galactose) \\
& - hexoses; \\
& - N-acetylglucosamine \\
\hline
\end{tabular}

Functional properties of LF are considered with account for its molecular structure. Glycoprotein is capable of iron binding and its transportation through intestinal mucus, thereby allowing regulation of iron ions in the body. It has the antibacterial and antiviral activities, facilitates tissue regeneration, regulation of cell growth and differentiation.

It was found that lactoferrin has the bacteriostatic activity and showed the special activity towards iron. LF is secreted and synthesized mainly in the iron-free form, which subsequently leads to its binding with free iron ions from the environment. This lactoferrin property significantly delays microbial growth including Gram-negative and Gram-positive bacteria and some yeasts. In physiological concentrations, lactoferrin facilitates membrane damage in Gram- negative bacteria, which results in liposaccharide liberation $[4,5]$.

LF protects mucous membranes from pathogenic microorganisms, has anti-inflammatory and immunomodulatory properties [6].

The antimicrobial properties of lactoferrin have been well studied in in vitro and in vivo experiments. For example, digestion of lactoferrin from maternal milk in the child stomach stimulates the growth of bifidobacteria, suppresses the growth of other microorganisms and determines the composition of indigenous intestinal microflora that is typical for infancy. This effect was proved when using mixtures for newborns $[4,7]$.
Besides the direct antimicrobial action, lactoferrin can influence the inflammatory process of infectious genesis. It was proved experimentally that lactoferrin protected from gastritis induced by Helicobacter pylori, maintained the integrity of intestinal mucosa, reduced lethality during infection with enterotoxigenic E. coli. The glycoproteid also takes part in the regulation of inflammation in neurodegenerative diseases, inflammatory bowel disease (IBD), skin allergy, lung diseases and arthritis [4].

Lang J., Yang N. et al. established that LF blocked cells with SARS-CoV [8]. This allowed carrying on investigations of LF clinical application in treating patients with COVID-19 [9].

GOST $33600-2015^{1}$ is used to determine lactoferrin in milk. The essence of the method consists in removal of fat and casein fraction of protein from a sample using a laboratory centrifuge and detection of the lactoferrin content by the method of reverse-phase HPLC with the use of a spectrometric detector at a wavelength of $205 \mathrm{~nm}$.

There are different methods for lactoferrin detection from bovine milk and whey obtained in cheese production. Another source for LF production at the industrial level is curd whey. Whey fractions or colostrum are considered the best LF sources for laboratory studies [10].

\section{Modern methods for lactoferrin extraction and production \\ Chromatographic methods (ion-exchange, affinity, cation-exchange chromatography)}

Most methods of LF extraction that allow obtaining protein in the native state are based on using chromatography with different preliminary stages of raw material preparation [11].

${ }^{1}$ GOST 33600-2015 "Milk and dairy products. Method for determination of the lactoferrin by high performance liquid chromatography". Moscow: Standartinform, 2019. - $11 \mathrm{p}$. 
Lactoferrin is mainly obtained from raw milk. There is a method for LF extraction by cation-exchange chromatography with the following purification and concentration using micro-, ultra-filtration and freeze drying. The choice of a method for LF extraction is based on the molecular properties of glycoproteid [12].

Another method for lactoferrin production from raw bovine milk is linked with chromatography on a column with sorbent SP Sepharose (Sulfopropyl-Sepharose) Big Beads equilibrated with $0.05 \mathrm{M}$ sodium phosphate buffer at $\mathrm{pH}=6.5$. Sorbent SP Sepharose Big Beads is a strong cation exchanger, which has granules with a size of $200 \mu \mathrm{m}$. Due to the large size of granules, milk flows through the column without its clogging. The use of this sorbent allows eliminating stages of fat removal and protein desalting, which shortens to a great extent the extraction process time. A degree of lactoferrin extraction by this method is more than $90 \%$ with protein purity of $95 \%[11,13]$.

The method of chromatographic single-stage industrial extraction and purification of bovine lactoferrin from dairy raw materials enables simultaneous recovery of not less than $90 \%$ of contained lactoferrin. This method uses the ion-exchange sorbent based on the hydrophilic macroporous acrylic polymer. This allows obtaining highly purified lactoferrin with preserved biological properties. With that, dairy raw materials used for this method can be subjected to following processing in the food industry.

\section{Membrane technologies for LF production}

Bovine lactoferrin was obtained for the first time on the industrial scale in Belgium in 1985. In 1989, the German company MILEI GmbH began production of lactoferrin from whey obtained in cheese and milk production by the technology developed by the Japanese company Morinaga Milk Industry Co., Ltd. engaged in production of food ingredients and functional products. About 600-700 thousand tons of milk per year were processed by the scheme of non-waste production. Lactoferrin yield was about 30 tons per year. The membrane technology was mainly used for lactoferrin extraction from defatted milk and cheese whey; purity of produced lactoferrin was not less than 96\% [10].

The method for production of the lactoferrin concentrate by the membrane adsorption method is well known. The method is quite expensive due to the use of import membrane cassettes and there is a possibility of penetrating particles of membrane fibers into dairy raw materials in the process of protein extraction [14].

The method for lactoferrin production enriched with immunoglobulins for prophylactic dietetic nutrition was patented. Colostrum of the first 24 hours of lactation, which is diluted with water to the density of milk, is used as a raw material. The obtained mixture is defatted using a separator; then, the casein fraction is precipitated by rennet; whey is obtained and sent to bactofugation with the following two-stage membrane filtration. As a result of filtration, lactoferrin and immunoglobulin remain between membranes. After that, retentate is dried or filled into containers. The obtained product preserves its native properties [15].

The price on lactoferrin from bovine milk on the world market depends on the level of its purification and quality, and varies from 50 to 500 dollars per $1 \mathrm{~kg}$ [16].

At present, more than 20 enterprises producing lactoferrin operate worldwide. The largest production units are in Germany, Japan and USA.

Lactoferrin is produced on the industrial scale by such companies as MILEI (Germany), DMV International (The Netherlands), DOMO Food Ingredients (Belgium), Fonterra (New Zealand), Tatura and Bega Cheese (Australia) and Glanbia Nutritionals (Ireland).

Preparations of imported highly purified lactoferrin are presented on the Russian market. They are intended mainly for the pharmaceutical industry, biochemical and medical investigations.

In Russia, food products with bovine lactoferrin are manufactured by small enterprises. A positive trend in whey processing using innovative technologies has been observed [17]. In infant formula production in the RF, the demand for lactoferrin is 50 tons per year [16].

\section{The use of lactoferrin in the food industry}

The use of lactoferrin in the meat industry

In the meat industry, lactoferrin is used to inhibit microbial vital activities. Meat raw material treatment consists in spraying of a LF-based preparation over a carcass or chilled cuts, which allows not only prevention of the microbial growth but also neutralization of the endotoxin activity [18].

In the USA, a dose of the lactoferrin application for meat preservation is not more than $65 \mathrm{mg} / \mathrm{kg}$. The USDA approved the use of lactoferrin as "processing aid" for carcass rinse treatments in 2002 [18]. Large companies began to introduce carcass treatment in production. A commercial form of lactoferrin, which is available as a processing aid for carcass treatments, is Activin provided by aLF Ventures LLC, joint venture between National Beef Packing Co., DMV International and Farmland Industries, located in Kansas City [19].

The antimicrobial action of lactoferrin is expressed in its ability to block attachment of bacteria to the surface of meat tissues. Moreover, interaction of lactoferrin with iron inhibits the microbial growth and prevents iron participation in oxidation reactions.

Spanish scientists studied the bactericidal activity of lactoferrin, its derivatives in combination with high hydrostatic pressure against six strains of three Gram-positive bacterial species Listeria monocytogenes, Staphylococcus aureus and Enterococcus faecalis in chicken breast.

Lactoferrin and its derivatives have a wide spectrum of antibacterial properties. However, these properties can be influenced by different factors such as temperature, water activity, $\mathrm{pH}$, composition of the medium, presence of salts, different protein, lipid or carbohydrate components [20]. 
For example, high hydrostatic pressure is used to increase microbial safety and extend product shelf life. However, its use in meat and meat products can lead to undesirable changes in color and texture. In addition, pressure influences the lactoferrin structure and activity, its antimicrobial properties and ability to bind and hold iron. Under the action of $400 \mathrm{MPa}$, the lactoferrin structure does not change significantly, but treatment under $500 \mathrm{MPa}$ and higher strongly affects LF properties, reduces its antimicrobial action [21]. For these reasons, the combined treatment of chicken breasts was used in the study.

During the experiment, samples of chicken breasts were inoculated with bacterial cultures, treated with antimicrobials based on lactoferrin and its derivatives in the concentration of 0.5 and $5 \mathrm{mg} / \mathrm{g}$ and subjected to high hydrostatic pressure processing (HHP) at $400 \mathrm{MPa}$ for $10 \mathrm{~min}$ at $10{ }^{\circ} \mathrm{C}$. During the study, the following groups of samples were investigated: samples prepared with addition of the antimicrobials and HHP treatment, samples treated only with pressure, and samples without added antimicrobials and without HHP treatment. Microbiological analyses were carried out on days 1, 3 and 9 and included counting of total viable bacteria [20].

The results of the study showed that the use of the antimicrobials based on lactoferrin and its derivatives with high hydrostatic pressure enhanced the bactericidal effect. Under the action of pressure, bacteria membranes are destroyed leading to an increase in sensitivity to the antimicrobials. This method provides food product safety without changes in quality indicators $[20,22]$.

An effect of hydrolysis and microwave treatment on the antibacterial activity of native bovine milk lactoferrin against Cronobacter sakazakii in different media was investigated in another study. The results showed that the antibacterial activity of the LF hydrolysates obtained with pepsin, chymosin and microbial rennet was higher than that of intact LF. The combined use of the LF hydrolysates with microwave heating demonstrated an increased inhibitory properties and inhibition of C. sakazakii after treatment at $450 \mathrm{~W}$ for $5 \mathrm{~s}\left(42^{\circ} \mathrm{C}\right)$ and $550 \mathrm{~W}$ for $5 \mathrm{~s}\left(50^{\circ} \mathrm{C}\right)$. Low intensity microwave treatment maintained product properties and enhanced the antibacterial activity of LF hydrolysates obtained with pepsin, chymosin and microbial rennet against C. sakazakii [23].

The antibacterial action of lactoferrin and high hydrostatic pressure (HHP) was also studied on the samples of cured beef carpaccio. The authors used activated lactoferrin (ALF), lactoperoxidase system (LPOS) and high hydrostatic pressure (HHP) treatments at $450 \mathrm{MPa}$ for $5 \mathrm{~min}$ against Listeria monocytogenes, Salmonella enterica subsp. enterica serovar Enteritidis and Escherichia coli $\mathrm{O}_{157}: \mathrm{H}_{7}$. Treated cured beef carpaccio was stored at $8{ }^{\circ} \mathrm{C}$ and $22^{\circ} \mathrm{C}$ for 7 days. It was found that the use of the antimicrobials and HHP treatment gave the synergistic effect and facilitated an increase in the microbiological safety of beef carpaccio [24].
A similar experiment with the use of lactoferrin, lactoperoxidase and high hydrostatic pressure (HHP) treatments (at $450 \mathrm{MPa}$ for $10 \mathrm{~min}$ ) against microorganisms (Listeria monocytogenes and Salmonella Enteritidis) was also carried out for dry-cured ham. After treatment, drycured ham was stored for 60 days at $8^{\circ} \mathrm{C}$. Microbiological analyses were carried out on 1, 15, 30 and 60 days of storage. In addition, the texture and color of the samples were investigated. The results of the experiment indicated that lactoferrin and lactoperoxidase did not affect L. monocytogenes and $S$. Enteritidis when applied individually, while the use of antimicrobials and HHP treatment inactivated $S$. Enteritidis. However, HHP treatment slightly changed color and texture of the samples [25].

Spanish scientists studied the lactoferrin antimicrobial effect in meat products and proved that lactoferrin, reuterin, lactoperoxydase in combination with high hydrostatic pressure (HHP) processing had the antimicrobial effect against Listeria monocytogenes, Salmonella enterica subsp. enterica serovar Enteritidis and Escherichia coli $\mathrm{O}_{157}$ : $\mathrm{H}_{7}$ in cooked ham. Two large pieces of cooked ham (900 g each) obtained from a market in Madrid and aseptically sliced in the laboratory conditions were used in the experiment. Ham slices $(20 \mathrm{~g})$ were inoculated with pathogenic microorganisms and held at $4{ }^{\circ} \mathrm{C}$ for $20 \mathrm{~h}$ before further treatment. The samples were divided into eight different groups: control (without using HHP and antimicrobials), samples with reuterin, samples with lactoperoxidase, samples with lactoferrin, samples treated with HHP, samples with reuterin + HHP, samples with lactoperoxidase + HHP and samples with lactoferrrin + HHP. All antimicrobials were added immediately before HHP treatment. Then, the samples were treated with HHP at $450 \mathrm{MPa}$ for $5 \mathrm{~min}$. After treatment, the samples were stored at temperatures of $4^{\circ} \mathrm{C}$ and $10^{\circ} \mathrm{C}$ for 35 days.

The results of the study showed that individual application of reuterin and lactoperoxydase affected the survival of pathogens; the S. Enteritidis and E. coli levels decreased. However, L. monocytogenes counts increased at a storage temperature of $4^{\circ} \mathrm{C}$. No effect was observed upon individual application of lactoferrin. When reuterin or lactoperoxydase were applied in combination with HHP, the synergistic antimicrobial effect against $L$. monocytogenes, $S$. Enteritidis and E. coli $\mathrm{O}_{157}: \mathrm{H}_{7}$ was found in cooked ham stored at $4^{\circ} \mathrm{C}$ and $10^{\circ} \mathrm{C}$ for 35 days. The $\mathrm{pH}$ and $\mathrm{a}_{\mathrm{w}}$ values were not changed significantly in all treated samples. Slight changes were found in color and shear strength values in treated cooked ham. Application of HHP individually or in combination with lactoperoxydase or lactoferrin reduced formation of volatile compounds in cooked ham during 35-day storage at $4{ }^{\circ} \mathrm{C}$ and $10{ }^{\circ} \mathrm{C}$. As a result, HHP treatment in combination with reuterin or lactoperoxydase was recommended as a hurdle technology against $L$. monocytogenes, $S$. Enteritidis and E. coli $\mathrm{O}_{157}: \mathrm{H}_{7}$ in cooked ham [26,27].

Synergetic antimicrobial effect of activated lactoferrin and rosemary extract in vitro was studied to improve meat 
storage technologies. The antimicrobial action was tested on Escherichia coli $\mathrm{O}_{15}: \mathrm{H}_{7}$, Salmonella Enteritidis and Listeria monocytogenes during meat storage. The researchers determined the minimum inhibitory concentrations (MICs) of activated lactoferrin, which were $1 \%$ for E. coli $\mathrm{O}_{15}: \mathrm{H}_{7}, 0.5 \%$ for $\mathrm{S}$. Enteritidis and $0.1 \%$ for L. monocytogenes. For example, while $15 \%$ rosemary extract inhibited L. monocytogenes, $30 \%$ rosemary extract partially inhibited the growth of E. coli $\mathrm{O}_{155}: \mathrm{H}_{7}$ and $S$. Enteritidis. The use of activated lactoferrin with rosemary extract enhanced the antimicrobial action of reagents, which allowed increasing storage duration of meat products [28].

Scientists from the Istanbul University studied an effect of different concentrations of nisin and lactoferrin (Lf), and their combination on the microbiological quality of Turkish-style meatballs. Meatballs were made by the traditional recipe from ground veal and treated with different concentrations of lactoferrin and/or nisin $(0,100$ and 200 $\mu \mathrm{g} / \mathrm{g})$. Samples were analyzed on days $0,1,3,5,7,10$ and 12 for microbiological parameters (total mesophilic aerobic bacteria, lactic acid bacteria, coliforms, Escherichia coli, total staphylococci, Staphylococcus aureus, total psychrophilic bacteria, Pseudomonas spp., sulfite-reducing anaerobic bacteria, yeasts and molds) and physicochemical characteristics ( $\mathrm{pH}$, water activity and moisture). It was found that the lowest level of microbiological spoilage was in the samples treated with the mixture of Lf $(200 \mu \mathrm{g} / \mathrm{g})$ and nisin $(100 \mu \mathrm{g} / \mathrm{g})$, which allowed extending shelf life of meatballs up to 10 days compared to the control samples with shelf life of only 3 days [29].

A search for effective methods for increasing microbiological safety of meat products is continued. The lactoferrin presence is not always regarded as the universal means for prevention of microbial colonization on the meat product surface. In 2006, for example, Korean scientists showed that low-fat, low-salt sausages treated with lactoferrin did not have longer shelf life compared to sausages not treated with it. According to the data of the model study, more than $0.25 \%$ of lactoferrin was required for a distinctive antimicrobial activity against the growth of E. coli $\mathrm{O}_{157}: \mathrm{H}_{7}$. However, extended shelf life during refrigerated storage was not achieved in the low-fat, low-salt sausages produced with the use of lactoferrin. Moreover, the synergistic effect of lactoferrin with sodium lactate was not found. The study showed that addition of lactoferrin into the low-fat sausages did not have the antimicrobial activity against E. coli $\mathrm{O}_{157}: \mathrm{H}_{7}$ due to the denaturation of lactoferrin or the complex process of sausage production, even though the distinctive antimicrobial effect was partly observed in the model study [30].

\section{The use of lactoferrin in other branches}

of the food industry

The practical use of lactoferrin in the food industry began from production of foods for child nutrition. Addition of lactoferrin into infant formulas facilitated an increase in the resistance of neonates to infections, improvement of intestinal microflora and reduction in the number of respiratory diseases [19]. From the technical viewpoint, lactoferrin in infant formulas prevents lipid oxidation allowing an increase in product shelf life. Production of infant formulas without lactoferrin in their composition is forbidden in some countries.

Bovine lactoferrin is used in production of different fermented products such as yogurt, kefir. These products facilitate stimulation of the bone tissue growth and elimination of rotavirus infection. The technology for functional yogurt preparation with prolonged shelf life was developed in the All-Russian Research Institute of Dairy Industry (VNIMI). Yogurt was produced by the reservoir method using the protosymbiotic starter culture. To increase product shelf life, whey protein lactoferrin having antimicrobial and bifidogenic properties was used. Addition of lactoferrin improved yogurt rheological characteristics and increased shelf life up to 14 days.

Besides dairy products and food additives, purified lactoferrin is added into canned foods, pharmaceutical preparations, sports nutrition, oral care products and cosmetics. Products with lactoferrin prevent the development of infections, strengthen the immune function, have the anti-inflammatory and antioxidant action. For example, a food supplement based on bovine lactoferrin and vitamin $\mathrm{C}$ encapsulated into a lipid bubble and having medicinal properties was registered in the European Union [9]. All the above allows classifying it as a novel, safe food product.

Lactoferrin also plays a part in wine production as a preserving agent. It inhibits the growth of yeasts Dekkera bruxellensis, which are a factor of wine spoilage, facilitating an increase in wine shelf life [31].

\section{Conclusion}

The application of lactoferrin as biologically active protein is expanding. The use of lactoferrin in the food industry should be considered promising for provision of food products with iron-binding component, enhancement of their immunomodulating character and antioxidant action, as well as an increase in product shelf-life. Based on the iron-binding capacity of lactoferrin, Russian scientists propose to use "iron-saturated forms of hololactoferrin from bovine milk as a domestic raw material for production of biologically active food additives and specialized food products".

Therefore, analysis of modern studies on the use of lactoferrin in food production shows that this component is actively used in dairy product manufacture and is of special importance for child nutrition. With that, studies on the use of lactoferrin in the meat industry are limited only to investigation of its bactericidal properties in treatment of meat semi-finished products.

Questions of protein introduction and preservation of its properties in meat products are still insufficiently investigated. In finished meat products, protein is not used as a biologically active additive. This is linked with the fact 
that lactoferrin is destroyed in the process of long thermal processing and loses its unique properties. A search for a method for production of a finished meat product containing lactoferrin is topical as meat consumption is growing in the conditions of the growth in income and living standards. An increase in animal proteins in diets of the population set a problem of increasing the biological activity of meat products. The use of lactoferrin in these products can change meat product quality by not only increasing shelf life but also by increasing their healthy properties.
Introduction of lactoferrin into meat systems will give an opportunity to obtain a functional product, which will have antiviral and anti-inflammatory properties and will also allow correction of the immune processes and enhance resistance of the body to overstrain and stress. To obtain such functional product, it is promising to use different lactoferrin modifications including encapsulation, for increasing thermal stability of protein during thermal treatment, which is one of the stages in meat product manufacture.

\section{REFERENCES}

1. Baker, E. N., Baker, H. M., Kidd, R. D. (2002). Lactoferrin and transferrin: Functional variations on a common structural framework. Biochemistry and Cell Biology, 80(1), 27-34. https://doi. org/10.1139/001-153

2. Farnaud, S. J.-C., Evans, R. W. (2003). Lactoferrina multifunctional protein with antimicrobial properties. Molecular Immunology, 40(7), 395-405. https://doi.org/10.1016/S01615890(03)00152-4

3. Krot, I.F. (2005). Lactoferrin's structure and functions and it's possible application in obstetrics. Health and environmental issues, 1(3), 65-69. (In Russian)

4. Brodsky, I.B., Bondarenko, V.M., Tomashevskaya, N.N., Sadchikova, E.R., Goldman, I.L. (2013). Antimicrobial, immunomodulating and prebiotic properties of lactoferrin. Bulletin of the Orenburg Scientific Center of the Ural Branch of the Russian Academy of Sciences, 4, 3. (In Russian)

5. Grammatikova, N.E., Rezvan, S.P., Nemtsova, E.R., Bezborodova, O.A., Tutykhina, I.L., Naroditsky, B.S. et al. (2010). In vitro study of antimicrobial activity of lactoferrins from various sources. Antibiotics and Chemotherapy, 55(7-8), 4. (In Russian)

6. Aleshina, G.N. (2019). Lactoferrin - an endogenous regulator of the protective functions of the organism. Medical academic journal, 19(1), 35-44. https://doi.org/10.17816/MAJ19135-44 (In Russian)

7. Bruni, N., Capucchio, M. T., Biasibetti, E., Pessione, E., Cirrincione, S., Giraudo, L. et al. (2016). Antimicrobial activity of lactoferrin-related peptides and applications in human and veterinary medicine. Molecules, 21(6), Article 752. https://doi. org/10.3390/molecules21060752

8. Lang, J., Yang, N., Deng, J., Liu, K., Yang, P., Zhang, G. et al. (2011). Inhibition of SARS pseudovirus cell entry by lactoferrin binding to heparan sulfate proteoglycans. PLOS ONE, 6(8), Article e23710. https://doi.org/10.1371/journal.pone.0023710

9. Serrano, G. Kochergina, I., Albors, A., Diaz, E., Oroval, M., Hueso, G., et al. (2020). Liposomal Lactoferrin as Potential Preventative and Cure for COVID-19. International Journal of Research in Health Sciences, 8(1), 8-15. https://doi.org/10.5530/ijrhs.8.1.3 10. Baker, E.N., Baker, H.M., Coon, N., Kidd, R.D. (2006). Lactoferrin: properties and applications. Dairy Industry, 2, 38-39. (In Russian)

11. Zobkova, Z.S., Michina, A.V., Smolyaninov, V.V., Shehvatova, G.V. (2009). Technology of lactoferrin extracting from raw milk. Dairy Industry, 12, 21-22. (In Russian)

12. Perraudin, J.-P., De Valck, L. (2020). Lactoferrin production from bovine milk or cheese whey. Journal of Engineering and Applied Sciences Technology, 2(1), 1-9. https://doi.org/10.47363/ JEAST/2019(1)103

13. Zobkova, Z.S., Gavrilina, A.D., Zenina, D.V., Fursova, T.P., Shelaginova, I.R. (2012). About some parameters of the process of isolation lactoferrine from milk. Dairy Industry, 9, 46-47. (In Russian)

14. Plate, K., Beutel, S., Buchholz, H., Demmer, W., Fischer-Frühholz, S., Reif, O. et al. (2006). Isolation of bovine lactoferrin, lactoperoxidase and enzymatically prepared lactoferricin from proteolytic digestion of bovine lactoferrin using adsorptive membrane chromatography. Journal of Chromatography A, 1117(1), 81-86. https://doi.org/10.1016/j.chroma.2006.03.090

15. Borzenkova, N.V., Balabushevich, N.G., Larionova, N.I. (2010). Lactoferrin: physical and chemical properties, biological functions, delivery systems, pharmaceutical and nutraceutical preparations (review). Russian Journal of Biopharmaceuticals, 2(3), 3-19. (In Russian)
16. Titov, E.I., Tikhomirova, N.A., Ionova, I.I. (2019). Investigation of the iron-binding capacity of the bovine lactoferrin. Problems of nutrition, 88(1), 91-96. https://doi.org/10.24411/0042-88332019-10011 (In Russian)

17. Skidan, I.N., Kaznacheev, K.S., Kirilova, A.V., Guljaev, A.E. (2015). The functional dietary components in infant formulas from goat milk. Clinical practice in pediatrics, 10(4), 38-48. (In Russian)

18. Naidu, A. S. (2002). Activated lactoferrin - A new approach to meat safety. Food Technology, 56(3), 40-45.

19. Sebranek, J. (2003). Activated Lactoferrin: A look at the Science. Meat Processing North American Edition. Retrieved from http://www.nterminus.com/sublinks/tradearticles/(17)\%20 Meat\%20Processing\%20(Nov\%202003).pdf Accessed April 05, 2021

20. Del Olmo, A., Calzada, J., Nuñez Manuel, M. (2012). Effect of lactoferrin and its derivatives against gram-positive bacteria in vitro and, combined with high pressure, in chicken breast fillets. Meat Science, 90(1), 71-76. https://doi.org/10.1016/j.meatsci.2011.06.003

21. Franco, I., Pérez, M. D., Castillo, E., Calvo, M., Sánchez, L. (2013). Effect of high pressure on the structure and antibacterial activity of bovine lactoferrin treated in different media. Journal of Dairy Research, 80(3), 283-290. https://doi.org/10.1017/ S0022029913000150

22. Franco, I., Pérez, M. D., Conesa, C., Calvo, M., Sánchez, L. (2018). Effect of technological treatments on bovine lactoferrin: An overview. Food Research International, 106, 173-182. https://doi.org/10.1016/j.foodres.2017.12.016

23. Harouna, S., Franco, I., Carramiñana, J. J., Blázquez, A., Abad, I., Pérez, M. D. et al. (2020). Effect of hydrolysis and microwave treatment on the antibacterial activity of native bovine milk lactoferrin against cronobacter sakazakii. International Journal of Food Microbiology, 319, Article 108495. https://doi.org/10.1016/j.ijfoodmicro.2019.108495

24. Bravo, D., de Alba, M., Medina, M. (2014). Combined treatments of high-pressure with the lactoperoxidase system or lactoferrin on the inactivation of listeria monocytogenes, salmonella enteritidis and escherichia coli $\boldsymbol{O}_{157}: \mathbf{H}_{7}$ in beef carpaccio. Food Microbiology, 41, 27-32. https://doi.org/10.1016/j. fm.2014.01.010

25. De Alba, M., Bravo, D., Medina, M. (2015). Inactivation of listeria monocytogenes and salmonella enteritidis in dry-cured ham by combined treatments of high pressure and the lactoperoxidase system or lactoferrin. Innovative Food Science and Emerging Technologies, 31, 54-59. https://doi.org/10.1016/j. ifset.2015.06.013

26. Montiel, R., Martín-Cabrejas, I., Medina, M. (2015). Reuterin, lactoperoxidase, lactoferrin and high hydrostatic pressure on the inactivation of food-borne pathogens in cooked ham. Food Control, 51, 122-128. https://doi.org/10.1016/j.foodcont.2014.11.010

27. Montiel, R., Martín-Cabrejas, I., Peirotén, Á., Medina, M. (2016). Reuterin, lactoperoxidase, lactoferrin and high hydrostatic pressure treatments on the characteristics of cooked ham. Innovative Food Science and Emerging Technologies, 35, 111-118. https://doi.org/10.1016/j.ifset.2016.04.013

28. Soyer, F., Keman, D., Eroğlu, E., Türe, H. (2020). Synergistic antimicrobial effects of activated lactoferrin and rosemary extract in vitro and potential application in meat storage. Journal of Food Science and Technology, 57(12), 4395-4403. https://doi. org/10.1007/s13197-020-04476-5 
29. Colak, H., Hampikyan, H., Bingol, E. B., Aksu, H. (2008). The effect of nisin and bovine lactoferrin on the microbiological quality of turkish-style meatball (Tekirdağ köfte). Journal of Food Safety, 28(3), 355-375. https://doi.org/10.1111/j.17454565.2008.00105.x

30. Lee, H. C., Chin, K. B. (2006). Product quality of low-fat/ salt sausages containing lactoferrin and antimicrobial activity against Escherichia coli $\mathrm{O}_{157}: \mathrm{H}_{7}$. Journal of Animal Resources Science, 48(4), 575-586.

31. Yilmaz, B., Tosun, X. (2014). The natural antimicrobial systems in milk and their utilization in food industry. Celal Bayar University Journal of Science, 1(9), 11-20.

\section{AUTHOR INFORMATION}

Irina V. Bobreneva - doctor of technical sciences, professor, professor, Department of Technology and biotechnology of meat and meat products, Moscow State University of Food Production. 11 Volokolamskoe shosse, 125080, Moscow, Russia. Tel.: +7-915-497-78-52, E-mail: BobrenevaIV@mgupp.ru

ORCID: http://orcid.org/0000-0002-2335-3760

* corresponding author

Mariya V. Rokhlova - postgraduate student, Department of of Technology and biotechnology of meat and meat products, Moscow State University of Food Production. 11 Volokolamskoe shosse, 125080, Moscow, Russia. Tel.: +7-906-086-03-84, E-mail: rohlovam@mail.ru ORCID: https://orcid.org/0000-0002-5580-2751

All authors bear responsibility for the work and presented data.

All authors made an equal contribution to the work.

The authors were equally involved in writing the manuscript and bear the equal responsibility for plagiarism.

The authors declare no conflict of interest. 